\title{
Molecular Subtypes Are Frequently Discordant Between Lesions in Patients With Synchronous Colorectal Cancer: Molecular Analysis of 59 Patients
}

\author{
KEIICHI ARAKAWA, KEISUKE HATA, HIROAKI NOZAWA, KAZUSHIGE KAWAI, TOSHIAKI TANAKA, \\ TAKESHI NISHIKAWA, KAZUHITO SASAKI, YASUTAKA SHUNO, MANABU KANEKO, MASAYA HIYOSHI, \\ SHIGENOBU EMOTO, KOJI MURONO, HIROFUMI SONODA, SATOSHI OKADA and SOICHIRO ISHIHARA
}

Department of Surgical Oncology, the University of Tokyo, Tokyo, Japan

\begin{abstract}
Background: We aimed to investigate the molecular features of synchronous colorectal cancer (CRC). Materials and Methods: Out of 1,262 patients with CRC, 130 lesions in 59 patients with synchronous CRC were retrospectively analyzed. Microsatellite, v-Ki-Ras2 Kristen rat sarcoma viral oncogene homolog (KRAS), v-raf murine sarcoma viral oncogene homolog B1 (BRAF), tumor protein 53 (TP53) and $\beta$-catenin status were evaluated and compared between synchronous CRC lesions in each patient. Results: The subtypes of instability, BRAF and $\beta$-catenin subtypes was significant but low. Patients with discordant KRAS and TP53 were not concordant between lesions in the same patient, and concordance of microsatellite KRAS/BRAF subtypes comprised $50.8 \%$ of those with synchronous CRC. The rate of patients with lesions containing both mutL homolog 1 (MLHI) methylation and microsatellite stable status was $66.7 \%$ in those with synchronous $C R C$, with at least one lesion with high microsatellite instability. Conclusion: The present study on synchronous CRC demonstrated a low concordance of molecular subtypes between lesions in the same patient. A molecular analysis of metastatic lesions is warranted for molecular targeted therapy of metastatic synchronous CRC.
\end{abstract}

Synchronous colorectal cancer (CRC) accounts for 1.1-8.1\% of all CRCs (1-3). The major pathways of CRC progression are through chromosomal instability (CIN) and microsatellite instability (MSI) (4). The CIN pathway in CRC typically

This article is freely accessible online.

Correspondence to: Keiichi Arakawa, MD, Department of Surgical Oncology, University of Tokyo Hospital, 7-3-1 Hongo, Bunkyo-ku, Tokyo 113-8655, Japan. Tel: +81 338155411 (ext. 37083), Fax: +81 338116822, e-mail: Keiichiarakawa@hotmail.com

Key Words: Colorectal cancer, MSI, MLH1 methylation, BRAF. includes the combination of mutations and loss of heterozygosity in tumor protein 53 (TP53) and adenomatous polyposis coli $(A P C)(5)$. There are three situations in which a patient may be predisposed to tumours arising from the MSI pathway; Lynch syndrome (LS), Lynch-like syndrome (LLS) and MLH1 methylation, all of which are associated with high MSI (MSI-H) (6). The presence of synchronous $\mathrm{CRC}$ is reported to have a relatively high correlation with the MSI pathway compared to solitary CRC $(4,6)$. The rate of MSI-H in solitary CRC is between $12-17 \%(4,6)$, while it is reportedly $30-37 \%$ in synchronous CRC (7-10) in Western countries; however, these reports were comprised of small numbers of patients with synchronous CRC.

There is a hypothesis that synchronous CRC arises due to the field effect. This has been reported in a small number of cases where long interspersed nucleotide element-1 (LINE1) methylation levels and $\mathrm{CpG}$ island methylator phenotype between lesions in each case are similar in those with synchronous CRC $(8,11)$. One of the predispositions for developing synchronous CRC is LS. Roth et al. reported that all lesions of patients with LS tend to show MSI-H (12). On the other hand, some reports suggested that microsatellite status was discordant between lesions in patients with synchronous CRC $(8,13)$. There were four reports investigating molecular subtypes such as v-Ki-Ras2 Kristen rat sarcoma viral oncogene homolog $(K R A S)$, v-raf murine sarcoma viral oncogene homolog B1 $(B R A F)$ and MSI $(8,13-15)$. In these reports, the concordance rate for MSI-H, KRAS-mutant and $B R A F$-mutant between lesions in the same case was $9-30 \%, 11-40 \%$ and $0-14 \%$, respectively. However, the study cohorts of these four reports were small (10 to 46 cases). Moreover, only one report performed a statistical analysis for the concordance of molecular subtypes between lesions in 10 cases with synchronous CRC (8).

The subtypes of $K R A S$ and $B R A F$ are directly linked to selection of patients for anti-epidermal growth factor receptor (EGFR) therapy (16). However, there are only a few reports on the concordance of $K R A S$ and $B R A F$ subtypes between 
lesions in cases of synchronous CRC $(17,18)$. Giannini et al. reported that $42 \%$ of cases with synchronous CRC had discordant subtypes of KRAS and BRAF (18). Furthermore, it is important to examine the MSI status of each lesion when selecting checkpoint blockade immunotherapy (19).

In the present study, we aimed to clarify the concordance of MSI, KRAS, BRAF, TP53, and $\beta$-catenin subtypes of lesions in patients with synchronous CRC, and further assessed the status of mismatch repair (MMR) genes by immunohistochemistry (IHC) and MLH1 methylation in those with MSI-H lesions.

\section{Materials and Methods}

In this study, we aimed to analyze the clinicopathological factors and molecular factors in patients with synchronous CRC, which we categorized as follows: patient-oriented and lesion-oriented.

Firstly, we conducted a retrospective study of 1,262 consecutive patients who underwent surgical resection for CRC at the Department of Surgical Oncology, University of Tokyo Hospital (Tokyo, Japan), between 2005 and 2015. Participants were stratified into either synchronous or solitary CRC groups. This study included 59 patients with synchronous CRC (comprising 130 lesions), and 1,203 patients with solitary CRC. Clinicopathological data including age, sex and other factors were collected from medical records. Patients with inflammatory bowel disease or familial adenomatous polyposis were excluded. Patients were excluded from molecular analysis of synchronous CRC if they had undergone preoperative chemoradiotherapy. Synchronous CRC was defined per the threepart definition by Warren and Gates (20): (i) the tumours had to be malignant, (ii) the tumours had to be separated from one another and not have metastasized, and (iii) the tumours had to have been diagnosed together, or at most 6 months apart. The extent of tumour progression was assessed according to the Union for International Cancer Control tumour-node-metastasis classification (21). In synchronous CRC, the index lesion was defined as the deepest tumour and the second lesion as the second deepest tumour in each patient. If the extent of invasion was same between the index and second lesion, the lesion with the largest diameter was defined as the index lesion. The clinicopathological characteristics of the index lesion were used in the patient-oriented analysis (22).

Secondly, the following molecular factors in synchronous CRC were analyzed in terms of patient-orientated data and lesion-orientated data: TP53, $\beta$-catenin, KRAS, BRAF and MSI. Moreover, mutL homolog $1(M L H 1)$ methylation and MMR [MLH1, postmeiotic segregation increased 2 (PMS2), mutS homolog 2 (MSH2), mutS homolog 6 (MSH6)] were evaluated in patients with synchronous $\mathrm{CRC}$ with MSI-H. The results of all molecular examinations were confirmed by two clinicians.

This study was approved by the Ethics Committees of the University of Tokyo [no. 3252-(7) and G3552-(5)].

Immunohistochemistry. All the samples for immunohistochemical analysis were obtained from paraffin-embedded (FFPE) specimens and stained as previously reported (23). The primary antibodies used were as follows: $\beta$-catenin (dilution 1:500; BD Transduction Laboratory, San Diego, CA, USA), TP53 (dilution 1:100; Dako, Glostrup, Denmark), MLH1 (dilution 1:50; Dako), PMS2 (dilution
1:50; Dako), MSH2 (dilution 1:50; EMD Millipore, Darmstadt, Germany), and MSH6 (dilution 1:50; BD Transduction Laboratory). The secondary antibody reaction was performed using Dako EnVision kit (Dako). Determination of staining for each antibody was performed as previously described (24-27). Briefly, positive status for $\beta$-catenin was defined as a score of more than two out of five points in this study according to staining of nuclei ( $0-2$ points), cytoplasm ( $0-2$ points) and cellular membrane ( $0-1$ point). A positive status for TP53 was defined as a nuclear staining rate of more than $50 \%$ of tumour cells.

Analysis of KRAS, BRAF and MSI. Tumour tissues were obtained from macrodissection of FFPE sections containing tumour tissues. Deoxyribonucleic acid (DNA) was extracted from tumour tissue using QIAamp DNA FFPE Tissue kit (Qiagen, Valencia, CA, USA) per the manufacturer's protocol. Direct sequencing of the extracted DNA was performed to evaluate mutations in KRAS codons 12 and 13 , and BRAF codon 600 . The sequence analysis of the BRAF codon 600 was outsourced (Eurofins Genomics, Tokyo, Japan). Microsatellite status was determined using the National Cancer Institute 5-marker scoring panel, including BAT25, BAT26, D2S123, $D 5 S 346$, and $D 17 S 250$. These loci were amplified by fluoresceinconjugated primers with sequence visualization by an ABI PRISM 3100 Genetic Analyzer (Applied Biosystems, Foster City, CA, USA), as previously reported (28-30). Status was defined as MSI$\mathrm{H}$ when two or more markers were unstable, MSI-low (MSI-L) when one marker was unstable, and microsatellite stable (MSS) when none of the markers were unstable.

MLH1 methylation. The methylation status of MLH1 was determined by a methylation-specific polymerase chain reaction (MSP) according to previously described methods (31). DNA from HT29 and SW480 cell lines, which were used as control samples (32), was extracted using a NucleoSpin Tissue kit (Takara Bio, Tokyo, Japan). DNA was bisulphite modified using a MethylEasy Xceed Rapid DNA Bisulphite Modification kit (Takara Bio). The specific primers for the methylated and unmethylated MSP were the same as described previously (33). The polymerase chain reaction (PCR) mixture contained $50 \mathrm{ng}$ bisulphite-modified or unmodified DNA and the MSP analysis was performed using an Episcope MSP kit (Takara Bio) according to the manufacturer's protocol. The PCR product was loaded onto a $2 \%$ agarose gel, stained with $0.5 \mathrm{~g} / \mathrm{ml}$ ethidium bromide, and visualized under ultraviolet (UV) illumination.

Statistical analyses. Continuous variables were compared using the Student's $t$-test or Mann-Whitney $U$-test, and categorical variables were compared using the chi-square test or Fisher's exact test. Concordance of molecular subtypes between the index and the second lesions for each patient was assessed with a $k$ statistic (8). Statistical analyses were conducted using JMP Pro version 13.0.0 (SAS Institute Inc., Cary, NC, USA). A $p$-value of less than 0.05 was considered significant.

\section{Results}

We compared the clinicopathological characteristics between 59 patients with synchronous CRC and 1,203 patients with solitary CRC (Table I). In terms of histopathology results, lesions with a mucinous component were significantly more frequent in patients with synchronous CRC than those with 
Table I. Clinicopathological features of patients with synchronous and solitary colorectal cancer.

\begin{tabular}{|c|c|c|c|c|c|}
\hline Characteristic & & $\begin{array}{c}\text { Total } \\
(\mathrm{N}=1,262)\end{array}$ & $\begin{array}{l}\text { Synchronous } \\
(\mathrm{N}=59 ; 4.7 \%)\end{array}$ & $\begin{array}{c}\text { Solitary } \\
(\mathrm{N}=1,203 ; 95.3 \%)\end{array}$ & $p$-Value \\
\hline Age, years & Median (range) & $67(26-93)$ & $69(37-90)$ & $67(26-93)$ & 0.3165 \\
\hline \multirow[t]{2}{*}{ Gender, n (\%) } & Male & $731(57.9)$ & $32(54.2)$ & $699(58.1)$ & 0.5582 \\
\hline & Female & $531(42.1)$ & $27(45.8)$ & $504(41.9)$ & \\
\hline $\mathrm{CEA}, \mathrm{ng} / \mathrm{ml}$ & Median (range) & $4.7(0.6-6,841)$ & $5.2(1-416)$ & $4.6(0.6-6,841)$ & 0.1339 \\
\hline \multirow[t]{2}{*}{ CEA level } & $<5 \mathrm{ng} / \mathrm{ml}$ & $661(52.8)$ & $26(44.1)$ & $635(52.8)$ & 0.1283 \\
\hline & $\geq 5 \mathrm{ng} / \mathrm{ml}$ & $601(47.2)$ & $33(55.9)$ & $568(47.2)$ & \\
\hline CA19-9, ng/ml & Median (range) & $12(1-13,250)$ & $13(1-698)$ & $12(1-13,250)$ & 0.5243 \\
\hline \multirow[t]{2}{*}{ CA19-9 level, n (\%) } & $<37 \mathrm{ng} / \mathrm{ml}$ & $1012(80.2)$ & $45(76.3)$ & $967(80.4)$ & 0.4491 \\
\hline & $\geq 37 \mathrm{ng} / \mathrm{ml}$ & $250(19.8)$ & $14(23.7)$ & $236(19.6)$ & \\
\hline \multirow[t]{2}{*}{ Tumour location, n (\%) } & Right & $392(31.1)$ & $15(25.4)$ & $377(31.3)$ & 0.0974 \\
\hline & Left & $870(68.9)$ & $44(74.6)$ & $826(68.7)$ & \\
\hline Diameter, mm & Median (range) & $40(5-155)$ & $40(12-120)$ & $40(5-155)$ & 0.1082 \\
\hline \multirow[t]{4}{*}{ Pathology, n (\%) } & WelI/mod & $1,165(92.3)$ & $46(78.0)$ & $1,119(93.0)$ & $<0.001$ \\
\hline & Poor/muc & $97(7.7)$ & $13(22.0)$ & $84(7.0)$ & \\
\hline & Poor & & $3(5.1)$ & $39(3.2)$ & 0.4720 \\
\hline & Muc & & $10(16.9)$ & $45(3.7)$ & $<0.001$ \\
\hline \multirow[t]{6}{*}{ T-Stage, n (\%) } & 1 & $159(12.6)$ & $3(5.1)$ & $156(13.0)$ & 0.1474 \\
\hline & 2 & $196(15.5)$ & $13(22.0)$ & $183(15.2)$ & \\
\hline & 3 & $584(46.3)$ & $26(44.1)$ & $558(46.4)$ & \\
\hline & 4 & $323(25.6)$ & $17(28.8)$ & $306(25.4)$ & \\
\hline & $\mathrm{T} 1+2$ & $353(27.9)$ & $15(25.4)$ & $338(28.1)$ & 0.6522 \\
\hline & $\mathrm{T} 3+4$ & $909(72.1)$ & $44(74.6)$ & 865 (71.9) & \\
\hline \multirow[t]{2}{*}{ Lymph node metastasis, n (\%) } & Absent & $707(56.0)$ & $31(52.5)$ & $676(56.2)$ & 0.5821 \\
\hline & Present & $555(44.0)$ & $28(47.5)$ & $527(43.8)$ & \\
\hline \multirow[t]{2}{*}{ Lymphatic invasion, n (\%) } & Absent & $854(67.7)$ & $42(71.2)$ & $812(67.5)$ & 0.5504 \\
\hline & Present & $408(32.3)$ & $17(28.8)$ & $391(32.5)$ & \\
\hline \multirow[t]{2}{*}{ Venous invasion, n (\%) } & Absent & $349(27.6)$ & $16(27.1)$ & $333(27.7)$ & 0.9248 \\
\hline & Present & $913(72.4)$ & $43(72.9)$ & $870(72.3)$ & \\
\hline \multirow[t]{6}{*}{ Stage, n (\%) } & I & $265(21.0)$ & 7 (11.9) & $258(21.5)$ & 0.2608 \\
\hline & II & $405(32.1)$ & $22(37.3)$ & $383(31.8)$ & \\
\hline & III & $424(33.6)$ & $23(39.0)$ & $401(33.3)$ & \\
\hline & IV & $168(13.3)$ & 7 (11.9) & $162(13.4)$ & \\
\hline & $\mathrm{I}+\mathrm{II}$ & $670(53.1)$ & $30(50.9)$ & $640(53.2)$ & 0.7189 \\
\hline & III+IV & $592(46.9)$ & $29(49.1)$ & $563(46.8)$ & \\
\hline
\end{tabular}

CA19-9: Carbohydrate antigen 19-9; CEA: carcinoembryonic antigen; Poor/muc: poorly differentiated adenocarcinoma or mucinous adenocarcinoma; well/mod: well- or moderately differentiated adenocarcinoma.

solitary CRC $[45(3.7 \%)$ vs. $10(16.9 \%) ; p<0.001]$. Other factors were not significantly different between the two groups.

Next, we performed molecular analysis on 130 lesions from the 59 patients with synchronous CRC (50 patients with double cancer, seven patients with triple, one patient with quadruple, and one patient with quintuple) (Table II). MSI-H status was observed in 12 out of 130 (9.2\%) lesions and nine out of $59(15.3 \%)$ patients. KRAS and BRAF mutations were observed in 45 out of $130(34.6 \%)$ lesions and 16 out of $130(12.3 \%)$ lesions, respectively. Positive staining of TP53 and $\beta$-catenin was observed in 60 out of 130 (46.1\%) lesions and 94 out of $130(72.3 \%)$ lesions, respectively.

We then divided the 130 synchronous CRC lesions into two groups: MSI-H (12 lesions) and MSS (118 lesions). Other molecular factors were compared between the two groups (Table III). In patients with $B R A F$ mutation, right- sidedness, mucinous and poorly differentiated pathology were more frequently seen in those with MSI-H vs. those with MSS lesions (BRAF mutation: $42.7 \%$ vs. $9.3 \%$, respectively, $p=0.0060$; right-sidedness: $58.3 \%$ vs. $24.6 \%$, respectively $p=0.0190$; mucinous and poorly differentiated type: $33.3 \%$ vs. $8.5 \%, p=0.0244$, respectively).

Next, we assessed the concordance of molecular subtypes between the index and the second lesions in each patient with synchronous CRC (Table IV). Subtypes of MSI, BRAF, and $\beta$-catenin correlated significantly between the index and second lesions in each patient. However, the $k$ coefficient for concordance was low (MSI: $k=0.3035, p=0.0146 ; B R A F$ : $k=0.4230, p=0.0010 ; \beta$-catenin: $k=0.3692, p=0.0085)$. Moreover, subtypes of KRAS and TP53 did not correlate significantly between the index and second lesions in each patient. 
Table II. Molecular features of synchronous colorectal cancer tumours.

\begin{tabular}{|c|c|c|c|c|c|c|}
\hline & & $\begin{array}{l}\text { All cases, } \mathrm{n}(\%) \\
\quad(\mathrm{N}=5)\end{array}$ & $\begin{array}{c}\text { All lesions, } \mathrm{n}(\%) \\
(\mathrm{N}=130)\end{array}$ & $\begin{array}{l}\text { Index lesion, } \mathrm{n}(\%) \\
\quad(\mathrm{N}=59 \text { lesions })\end{array}$ & $\begin{array}{l}\text { Other lesions, } \mathrm{n}(\%) \\
\quad(\mathrm{N}=71 \text { lesions })\end{array}$ & $p$-Value \\
\hline \multirow[t]{2}{*}{ Microsatellite status } & MSS & $50(84.7)$ & $118(90.8)$ & $52(88.1)$ & $66(92.9)$ & 0.3453 \\
\hline & MSI-H & $9(15.3)$ & $12(9.2)$ & 7 (11.9) & $5(7.1)$ & \\
\hline \multirow[t]{2}{*}{$K R A S$} & Wild-type & $24(40.7)$ & $85(65.4)$ & $42(71.2)$ & $43(60.6)$ & 0.2033 \\
\hline & Mutant & $35(59.3)$ & 45 (34.6) & $17(28.8)$ & $28(39.4)$ & \\
\hline \multirow[t]{2}{*}{$B R A F$} & Wild-type & $47(79.7)$ & $114(87.7)$ & $52(88.1)$ & $62(87.3)$ & 0.8884 \\
\hline & Mutant & $12(20.3)$ & $16(12.3)$ & 7 (11.9) & $9(12.7)$ & \\
\hline \multirow[t]{2}{*}{ TP53 } & Negative & $31(52.5)$ & $70(53.9)$ & $31(52.5)$ & $39(54.9)$ & 0.7858 \\
\hline & Positive & $28(47.5)$ & $60(46.1)$ & $28(47.5)$ & $32(45.1)$ & \\
\hline \multirow[t]{2}{*}{$\beta$-Catenin } & Negative & $17(28.8)$ & $36(27.7)$ & $17(28.8)$ & $19(26.8)$ & 0.7947 \\
\hline & Positive & $42(71.2)$ & $94(72.3)$ & $42(71.2)$ & $52(73.2)$ & \\
\hline
\end{tabular}

MSI-H: High microsatellite instability; MSS: microsatellite stable. Other lesions: Lesions including the 2nd, 3rd, 4th and 5th lesions.

Because anti-EGFR therapy is effective only for those with $K R A S$ or $B R A F$ wild-type tumours, whether the tumour is wild-type for $K R A S$ and $B R A F$ is important. We thus assessed the rate of different subtypes between lesions for each patient according to subtype of KRAS and BRAF (Figure 1). In this analysis, we divided patients into three groups according to subtype of $K R A S$ and $B R A F$ : namely those whose lesions only had wild-type $K R A S$ or $B R A F$; those whose lesions only had mutant $K R A S$ or $B R A F$; and others which included both wild-type and mutant $K R A S$ or $B R A F$ (Figure 1A and $\mathrm{B}$ ). We found that the number of patients with lesions wild-type for both KRAS and BRAF was 20 out of 59 cases (33.9\%), the number of patients with all mutant-type $K R A S$ and $B R A F$ lesions was nine out of 59 cases $(15.3 \%)$, and 30 out of 59 cases $(50.8 \%)$ had lesions with wild-type and mutant KRAS or BRAF (Figure 1C).

In this study, the number of patients with MSI-H lesions was nine out of 59 (15.3\%) patients with synchronous CRC. Following this, we assessed the cause of MSI-H status of 12 lesions in nine patients. MLH1 methylation was seen in eight out of 12 MSI-H lesions (66.7\%). Moreover, we also performed IHC for MMR on MSI-H lesions. By referring to the results of these molecular analyses, we predicted the disease type for each MSI-H case (Table V). Germline genetic testing is necessary for the definitive diagnosis of LS (34). For ethical reasons, we did not perform germline genetic testing on the patients. Most previous studies investigating patients with synchronous CRC also report performing only an MMR analysis without analysis of MLH1 methylation (24). Carcinogenesis in synchronous CRC can be analysed in detail through IHC staining for MMR-associated proteins and determining the $M L H I$ methylation status.

In total, eight out of 12 lesions (66.7\%) showed evidence of MLH1 methylation and loss of MLH1/PMS2 expression. On the other hand, the other four lesions consisted of three lesions with loss of MSH2/MSH6 and a lesion with loss of
PMS2 expression, which were suspected to be associated with LS or LLS. All lesions in cases 1 and 2 indicated MSI$\mathrm{H}$. The other seven cases showed evidence of containing a combination of MSI-H and MSS. In case 1, loss of MSH2/MSH6 staining was observed in both lesions. This case was considered LS or LLS because neither $M L H 1$ methylation nor BRAF mutation was present (35). We did not perform genetic testing, thus we were unable to differentiate between LS and LLS. In case 2, one lesion showed evidence of $M L H 1$ methylation, while the other lesion demonstrated loss of PMS2 staining alone without MLH1 methylation. This was presumably a case with both LLS and MLH1 methylation lesions. For Cases 5-9, lesions with both $M L H 1$ methylation and MSS concurrently were seen, because only one of the lesions showed MSI-H, the loss of MLH1/PMS2 and the presence of $\mathrm{MLHI}$ methylation. Additionally, we summarized our subgroups of 59 synchronous CRC cases (Figure 2).

\section{Discussion}

In this study, we examined the concordance between lesions in patients with MSI, KRAS, BRAF, TP53 and $\beta$-catenin subtypes for 59 synchronous CRC cases which consisted of 130 lesions in total. There was only one report previously in which a statistical analysis of concordance between lesions in patients with synchronous CRC was performed (8). Our molecular analysis showed that the concordance between lesions was low, which might become clinically important for molecular targeting therapy.

The concordance of MSI, BRAF and $\beta$-catenin between the index and the second lesions in patient was significant but low. The subtypes of KRAS and TP53 did not correlate significantly between the index and the second lesions. Regarding MSI status, $15.3 \%$ of synchronous CRC cases had MSI-H lesions and only two cases concordant for MSI-H 


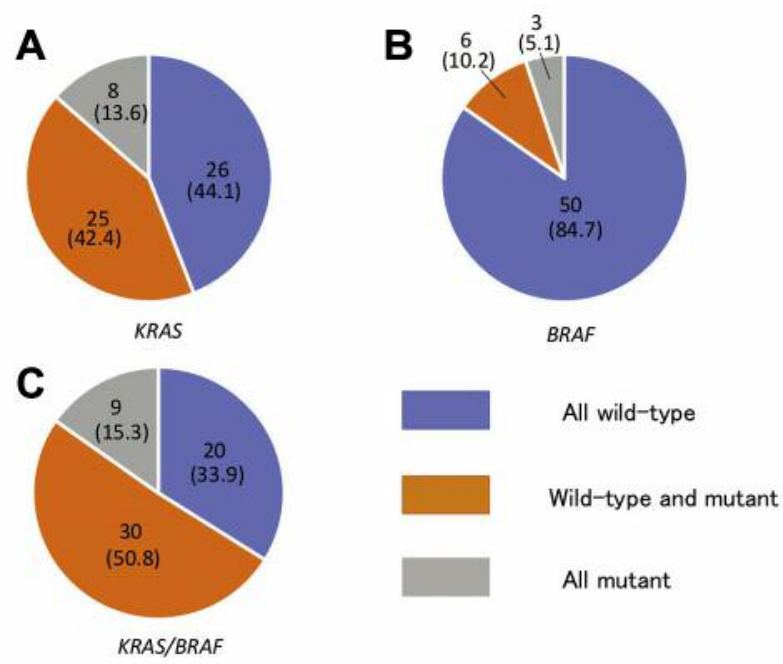

Figure 1. Schematic overview of the subtypes of v-Ki-Ras2 Kristen rat sarcoma viral oncogene homolog (KRAS) (A) and v-raf murine sarcoma viral oncogene homolog $B 1(B R A F)(B)$ alone and in combination $(C)$ from 59 patients with synchronous colorectal cancer. Patients were divided into three groups: patients with all lesions consisting of wildtype, patients with lesions including both wild-type and mutant, and patients with lesions only of mutant type. Data are number of patients with percentages in parentheses.

were observed. The investigation of $M L H 1$ methylation and expression of MMR proteins in patients with MSI-H lesions revealed six out of nine $(66.7 \%)$ cases to have MSI-H lesions with $M L H 1$ methylation, concurrent with a lesion with MSS. In this study, molecular subtypes representative of the CIN and MSI pathways were not concordant between lesions in patients with synchronous CRC. These results might indicate that there were few cases which had mechanisms that explain carcinogenesis in a unified way in patients with synchronous CRC. Many patients were found to have sporadic carcinogenesis with CIN and $M L H 1$ methylation-associated carcinogenesis might occur separately. These results suggest that synchronous CRC lesions develop individually through different pathways of carcinogenesis.

In this study, the rate of MSI-H-concordant cases accounted for two out of 59 synchronous CRC cases (3.4\%), which is somewhat lower that what was previously reported: $13.2-34.0 \%$ in Western countries $(7,8,10,13)$. The prevalence of MSI-H lesions in patients with synchronous $\mathrm{CRC}$ in the present study was relatively lower than the prevalence reported in Western countries. The frequency of LS was reported to be approximately $3-8 \%$ in the West (34), while that for Japan was $0.7 \%$ (36). Furthermore, the low rate of LS in Japanese patients might be the reason for low MSI-H concordance among patients with synchronous CRC in this study.

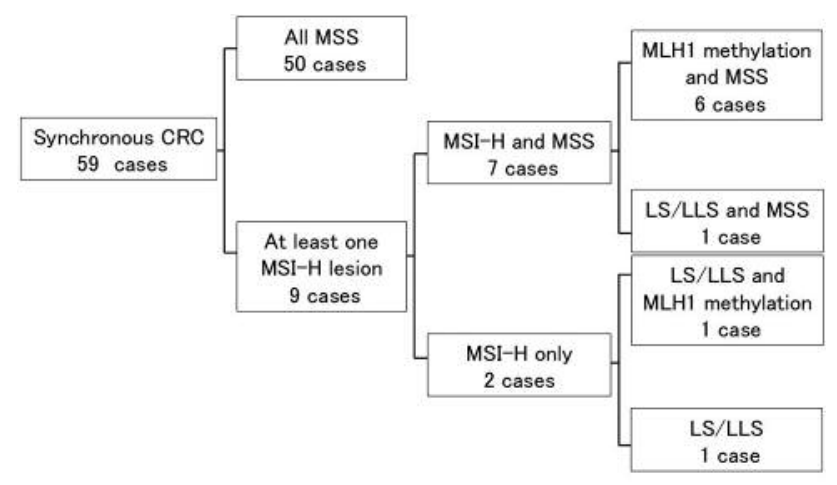

Figure 2. Classification of 59 patients with synchronous colorectal cancer (CRC). Patients were divided into 50 cases lesions with MSS and nine with high microsatellite instability (MSI-H). LLS: Lynch-like syndrome; LS: Lynch syndrome.

In this study, the concordance rates of $K R A S$ and $B R A F$ subtypes among cases of synchronous CRC were less than $50 \%$. This suggests that in synchronous CRC each lesion may arise from a different pathway. Moreover, these results may become clinically important. Anti-EGFR therapy (16) and checkpoint blockade immunotherapy (19) are effective only for lesions with wild-type $K R A S$ and $B R A F$ and lesions with loss of MMR protein expression in CRC. If the status of $K R A S$ and $B R A F$ differs between lesions in a patient with synchronous CRC, the status of KRAS and BRAF associated with recurrent metastases might not be clear. Therefore, $K R A S$ and BRAF status at the site of recurrence should ideally be investigated when considering anti-EGFR therapy. If the tissue from where recurrent metastases occurred cannot be obtained, liquid biopsy might be useful to examine $K R A S$ or BRAF status in the future (37).

Our study has several limitations. Firstly, no germline genetic testing for LS was conducted and we were not able to differentiate LS from LLS in this study. However, the rate of LS in this study was suspected to be low, approximately $0.7 \%$ according to a previous report in Japan (36). Secondly, we did not examine all subtypes of RAS in lesions of patients with synchronous CRC. We examined only subtypes of KRAS codon 12 and 13 because the rate of other RAS mutations other than KRAS codon 12 and 13 were fewer than $10 \%$ of all $R A S$ mutations $(38,39)$. Thus, we were able to cover more than $90 \%$ of all RAS mutations in the present study. Thirdly, the molecular analysis carried out for lesions with synchronous CRC was not performed for those with solitary CRC. In this study, rather we focused on relationships between different lesions in each patient with synchronous CRC.

In conclusion, the present study on synchronous CRC demonstrated low concordance of molecular subtypes between lesions in individual patients. These findings 
Table III. Correlation between microsatellite status and other features of synchronous colorectal cancer tumours.

\begin{tabular}{llccc}
\hline Feature & & $\begin{array}{c}\text { MSI-H } \\
\text { N=12 } \\
\text { lesions }\end{array}$ & $\begin{array}{c}\text { MSS } \\
\text { N=118 } \\
\text { lesions }\end{array}$ & $p$-Value \\
& & $7(58.3)$ & $29(24.6)$ & 0.0190 \\
Location, n (\%) & Right side & $5(41.7)$ & $89(75.4)$ & \\
& Left side & $4(33.3)$ & $63(53.4)$ & 0.1823 \\
T-Stage, n (\%) & T1+2 & $8(66.7)$ & $55(46.6)$ & \\
& T3+4 & $8(66.7)$ & $108(91.5)$ & 0.0244 \\
Pathology, n (\%) & WelI/mod & $4(33.3)$ & $10(8.5)$ & \\
& Poor/muc & $9(75.0)$ & $76(64.4)$ & 0.4516 \\
KRAS, n (\%) & Wild-type & $3(25.0)$ & $42(35.6)$ & \\
& Mutant & $7(58.3)$ & $107(90.7)$ & 0.0060 \\
BRAF, n (\%) & Wild-type & $5(41.7)$ & $11(9.3)$ & \\
& Mutant & $8(66.7)$ & $62(52.5)$ & 0.3443 \\
TP53, n (\%) & Negative & $4(33.3)$ & $56(47.5)$ & \\
& Positive & $5(41.7)$ & $31(26.3)$ & 0.2735 \\
$\beta$-Catenin, n (\%) & Negative & $57(73.7)$ & \\
& Positive & $7(58.3)$ & $87\left(\begin{array}{ccc} \\
\end{array}\right.$ &
\end{tabular}

MSI-H: High microsatellite instability; MSS: microsatellite stable; $K R A S$ : v-Ki-Ras2 Kristen rat sarcoma viral oncogene homolog; $B R A F$ v-raf murine sarcoma viral oncogene homolog B1; TP53: tumor protein 53; Poor/muc: poorly differentiated adenocarcinoma or mucinous adenocarcinoma; weIl/mod: well- or moderately differentiated adenocarcinoma. Data are frequencies of patients.
Table IV. Concordance of molecular markers for 59 synchronous colorectal cancer cases.

\begin{tabular}{|c|c|c|c|c|c|}
\hline \multirow{3}{*}{$\begin{array}{l}\text { Index lesion } \\
\text { Microsatellite }\end{array}$} & \multicolumn{5}{|c|}{ Concordance } \\
\hline & \multicolumn{2}{|c|}{$\begin{array}{c}\text { Second lesion, } \\
\mathrm{n}(\%)\end{array}$} & \multirow[t]{2}{*}{$\begin{array}{c}\text { Concordance } \\
\text { rate }\end{array}$} & \multirow[t]{2}{*}{$\begin{array}{c}k \\
\text { Value }\end{array}$} & \multirow[t]{2}{*}{$p$-Value } \\
\hline & MSS & MSI-H & & & \\
\hline MSS & $50(84.8)$ & $2(3.4)$ & 0.88 & 0.3035 & 0.0146 \\
\hline MSI-H & $5(8.5)$ & $2(3.4)$ & & & \\
\hline$K R A S$ & Wild-type & Mutant & & & \\
\hline Wild-type & $28(47.5)$ & $14(23.7)$ & 0.61 & 0.1262 & 0.3234 \\
\hline Mutant & $9(15.3)$ & $8(13.6)$ & & & \\
\hline$B R A F$ & Wild-type & Mutant & & & \\
\hline Wild-type & $47(79.7)$ & $5(8.5)$ & 0.86 & 0.4230 & 0.0010 \\
\hline Mutant & $3(5.1)$ & $4(6.8)$ & & & \\
\hline TP53 & Negative & Positive & & & \\
\hline Negative & $15(25.4)$ & $16(27.1)$ & 0.46 & 0.0876 & 0.5012 \\
\hline Positive & $16(27.2)$ & $12(20.3)$ & & & \\
\hline$\beta$-Catenin & Negative & Positive & & & \\
\hline Negative & $9(15.3)$ & $8(13.6)$ & 0.75 & 0.3692 & 0.0085 \\
\hline Positive & 7 (11.9) & $35(59.3)$ & & & \\
\hline
\end{tabular}

MSI-H: High microsatellite instability; MSS: microsatellite stable; $K R A S$ : v-Ki-Ras2 Kristen rat sarcoma viral oncogene homolog; $B R A F$ : $\mathrm{v}$-raf murine sarcoma viral oncogene homolog B1; TP53: tumor protein 53

Table V. Methylation and MMR status of MSI cases in synchronous CRC.

\begin{tabular}{|c|c|c|c|c|c|c|c|c|c|c|c|c|}
\hline Case & Gender & $\begin{array}{l}\text { Age, } \\
\text { years }\end{array}$ & $\begin{array}{l}\text { Family } \\
\text { history* }\end{array}$ & Location & MSI & Methylation & $\begin{array}{c}\text { MMR } \\
\text { loss }\end{array}$ & $K R A S$ & $B R A F$ & $\beta$-Catenin & ТP53 & $\begin{array}{l}\text { Suspected } \\
\text { condition }\end{array}$ \\
\hline \multirow[t]{2}{*}{1} & Male & 55 & - & $\mathrm{C}$ & MSI-H & - & MSH2/MSH6 & Wild-type & Wild-type & + & - & LS, LLS \\
\hline & & & & $\mathrm{S}$ & MSI-H & - & MSH2/MSH6 & G12D & Wild-type & + & + & LS, LLS \\
\hline \multirow[t]{2}{*}{2} & Male & 68 & - & S & MSI-H & + & MLH1/PMS2 & G12V & Wild-type & + & - & Methylation \\
\hline & & & & $\mathrm{R}$ & MSI-H & - & PMS2 & Wild-type & Wild-type & + & + & LS, LLS \\
\hline \multirow[t]{2}{*}{3} & Male & 53 & - & S & MSS & & & Wild-type & V600E & + & + & \\
\hline & & & & $\mathrm{R}$ & MSI-H & - & MSH2/MSH6 & Wild-type & Wild-type & - & - & LS, LLS \\
\hline \multirow[t]{3}{*}{4} & Female & 85 & - & $\mathrm{S}$ & MSS & & & Wild-type & Wild-type & + & + & \\
\hline & & & & $\mathrm{C}$ & MSI-H & + & MLH1/PMS2 & Wild-type & V600E & - & - & Methylation \\
\hline & & & & $\mathrm{D}$ & MSI-H & + & MLH1/PMS2 & G12V & Wild-type & + & + & Methylation \\
\hline \multirow[t]{2}{*}{5} & Male & 70 & & $\mathrm{C}$ & MSI-H & + & MLH1/PMS2 & Wild-type & V600E & - & - & Methylation \\
\hline & & & & $\mathrm{S}$ & MSS & & & Wild-type & Wild-type & - & - & \\
\hline \multirow[t]{3}{*}{6} & Female & 80 & - & $\mathrm{T}$ & MSI-H & + & MLH1/PMS2 & Wild-type & V600E & + & - & Methylation \\
\hline & & & & A & MSS & & & Wild-type & V600E & + & + & \\
\hline & & & & $\mathrm{S}$ & MSS & & & G12V & Wild-type & + & - & \\
\hline \multirow[t]{3}{*}{7} & Male & 55 & - & $\mathrm{C}$ & MSI-H & + & MLH1/PMS2 & Wild-type & V600E & + & - & Methylation \\
\hline & & & & $\mathrm{D}$ & MSS & & & Wild-type & Wild-type & + & - & \\
\hline & & & & A & MSS & & & G13D & Wild-type & - & + & \\
\hline \multirow[t]{2}{*}{8} & Female & 78 & + & A & MSI-H & + & MLH1/PMS2 & Wild-type & Wild-type & - & - & Methylation \\
\hline & & & & $\mathrm{S}$ & MSS & & & Wild-type & Wild-type & - & - & \\
\hline \multirow[t]{2}{*}{9} & Female & 76 & - & A & MSI-H & + & MLH1/PMS2 & Wild-type & V600E & - & + & Methylation \\
\hline & & & & $\mathrm{S}$ & MSS & & & G12A & Wild-type & + & - & \\
\hline
\end{tabular}

LS: Lynch syndrome; LLS: Lynch like syndrome; Methylation: hMLH1 methylated status; MSI-H: high microsatellite instability; MSS: microsatellite stable; KRAS: v-Ki-Ras2 Kristen rat sarcoma viral oncogene homolog; BRAF: v-raf murine sarcoma viral oncogene homolog B1; TP53: tumor protein 53 . *History of LS-associated cancer. 
suggest that each lesion in synchronous CRC arises individually through a different pathway. In clinical practice, these results suggest it may be useful to perform a molecular analysis on recurrent metastases and construct a treatment strategy based on the results when selecting molecular targeting therapy.

\section{Conflicts of Interest}

None.

\section{Authors' Contributions}

KA, KH, HN, KK, TT, TN, KS, YS, MK, MH, SE, KM, HS, SO and SI contributed to the conception, design, or acquisition of data, or analysis and interpretation of data; drafting the article or revising it critically for important intellectual content; and approved the final version for publication.

\section{Acknowledgements}

This research was supported by Grants-in-Aid for Scientific Research (C) (grant numbers: 16K07143, 16K07161, 17K10620, 17K10621, 17K10623, and 18K07194) from the Japan Society for the Promotion of Science and by the Project for Cancer Research and Therapeutic Evolution (grant number: 18cm0106502h0003) from the Japan Agency for Medical Research and Development.

\section{References}

1 Latournerie M, Jooste V, Cottet V, Lepage C, Faivre J and Bouvier AM: Epidemiology and prognosis of synchronous colorectal cancers. Br J Surg 95: 1528-1533, 2008. PMID: 18991301. DOI: 10.1002/bjs.6382

2 Lam AK, Chan SS and Leung M: Synchronous colorectal cancer: clinical, pathological and molecular implications. World J Gastroenterol 20: 6815-6820, 2014. PMID: 24944471. DOI: 10.3748/wjg.v20.i22.6815

3 Huang CS, Yang SH, Lin CC, Lan YT, Chang SC, Wang HS, Chen WS, Lin TC, Lin JK and Jiang JK: Synchronous and metachronous colorectal cancers: distinct disease entities or different disease courses? Hepato Gastroenterol 62: 286-290, 2015. PMID: 26902012. DOI: 10.5754/hge13389

4 Grady WM and Carethers JM: Genomic and epigenetic instability in colorectal cancer pathogenesis. Gastroenterology 135: 1079-1099, 2008. PMID: 18773902. DOI: 10.1053/ j.gastro.2008.07.076

5 Comprehensive molecular characterization of human colon and rectal cancer. Nature 487: 330-337, 2012. PMID: 22810696. DOI: $10.1038 /$ nature 11252

6 Boland CR and Goel A: Microsatellite instability in colorectal cancer. Gastroenterology 138: 2073-2087, 2010. PMID: 20420947. DOI: $10.1053 /$ j.gastro.2009.12.064

7 Pedroni M, Tamassia MG, Percesepe A, Roncucci L, Benatti P, Lanza GJ, Gafa R, Di Gregorio C, Fante R, Losi L, Gallinari L, Scorcioni F, Vaccina F, Rossi G, Cesinaro AM and Ponz de Leon M: Microsatellite instability in multiple colorectal tumors. Int J Cancer 81: 1-5, 1999. PMID: 10077143.
8 Nosho K, Kure S, Irahara N, Shima K, Baba Y, Spiegelman D, Meyerhardt JA, Giovannucci EL, Fuchs CS and Ogino S: A prospective cohort study shows unique epigenetic, genetic, and prognostic features of synchronous colorectal cancers. Gastroenterology 137: 1609-1620, 2009. PMID: 19686742. DOI: 10.1053/j.gastro.2009.08.002

9 Dykes SL, Qui H, Rothenberger DA and Garcia-Aguilar J: Evidence of a preferred molecular pathway in patients with synchronous colorectal cancer. Cancer 98: 48-54, 2003. PMID: 12833454. DOI: $10.1002 / \mathrm{cncr} .11445$

$10 \mathrm{Hu} \mathrm{H}$, Chang DT, Nikiforova MN, Kuan SF and Pai RK: Clinicopathologic features of synchronous colorectal carcinoma: A distinct subset arising from multiple sessile serrated adenomas and associated with high levels of microsatellite instability and favorable prognosis. Am J Surg Pathol 37: 1660-1670, 2013. PMID: 23887157. DOI: 10.1097/PAS.0b013e31829623b8

11 Giovannucci E and Ogino S: DNA methylation, field effects, and colorectal cancer. J Natl Cancer Inst 97: 1317-1319, 2005. PMID: 16174847. DOI: 10.1093/jnci/dji305

12 Roth RM, Haraldsdottir S, Hampel H, Arnold CA and Frankel WL: Discordant mismatch repair protein immunoreactivity in Lynch syndrome-associated neoplasms: A recommendation for screening synchronous/metachronous neoplasms. Am J Clin Pathol 146: 5056, 2016. PMID: 27357288. DOI: 10.1093/ajcp/aqw067

13 Bae JM, Cho NY, Kim TY and Kang GH: Clinicopathologic and molecular characteristics of synchronous colorectal cancers: Heterogeneity of clinical outcome depending on microsatellite instability status of individual tumors. Dis Colon Rectum 55: 181-190, 2012. PMID: 22228162. DOI: 10.1097/DCR.0b013 e31823c46ce

14 Zauber P, Huang J, Sabbath-Solitare M and Marotta S: Similarities of molecular genetic changes in synchronous and metachronous colorectal cancers are limited and related to the cancers' proximities to each other. J Mol Diagn 15: 652-660, 2013. PMID: 23810502. DOI: 10.1016/j.jmoldx.2013.03.009

15 Jesinghaus M, Pfarr N, Kloor M, Endris V, Tavernar L, Muckenhuber A, von Knebel Doeberitz M, Penzel R, Weichert $\mathrm{W}$ and Stenzinger A: Genetic heterogeneity in synchronous colorectal cancers impacts genotyping approaches and therapeutic strategies. Genes Chromosom Cancer 55: 268-277, 2016. PMID: 26650777. DOI: $10.1002 /$ gcc .22330

16 Van Cutsem E, Cervantes A, Adam R, Sobrero A, Van Krieken JH, Aderka D, Aranda Aguilar E, Bardelli A, Benson A, Bodoky G, Ciardiello F, D'Hoore A, Diaz-Rubio E, Douillard JY, Ducreux M, Falcone A, Grothey A, Gruenberger T, Haustermans K, Heinemann V, Hoff P, Köhne CH, Labianca R, Laurent-Puig P, Ma B, Maughan T, Muro K, Normanno N, Österlund P, Oyen WJG, Papamichael D, Pentheroudakis G, Pfeiffer P, Price TJ, Punt C, Ricke J, Roth A, Salazar R, Scheithauer W, Schmoll HJ, Tabernero J, Taïeb J, Tejpar S, Wasan H, Yoshino T, Zaanan A and Arnold D: ESMO Consensus Guidelines for the Management of Patients with Metastatic Colorectal Cancer. Ann Oncol 27: 1386-1422, 2016. PMID: 27380959. DOI: 10.1093/ annonc/mdw235

17 de Macedo MP, de Melo FM, Ribeiro Jda S, de Mello CA, de Souza Begnami MD, Soares FA, Carraro DM, da Cunha IW: RAS mutations vary between lesions in synchronous primary colorectal cancer: Testing only one lesion is not sufficient to guide anti-EGFR treatment decisions. Oncoscience 2: 125-130, 2015. PMID: 25859555. DOI: 10.18632/oncoscience. 118 
18 Giannini R, Lupi C, Loupakis F, Servadio A, Cremolini C, Sensi E, Chiarugi M, Antoniotti C, Basolo F, Falcone A and Fontanini G: KRAS and BRAF genotyping of synchronous colorectal carcinomas. Oncol Lett 7: 1532-1536, 2014. PMID: 24765171. DOI: $10.3892 /$ ol.2014.1905

19 Xiao Y and Freeman GJ: The microsatellite instable subset of colorectal cancer is a particularly good candidate for checkpoint blockade immunotherapy. Cancer Dis 5: 16-18, 2015. PMID: 25583798. DOI: 10.1158/2159-8290.CD-14-1397

20 Warren S and Gates O: Multiple primary malignant tumors: a survey of the literature and statistical study. Am J Cancer 16: 1358-1414, 1932.

21 Gospodarowicz MK, Brierley JD and Wittekind C: TNM Classification of Malignant Tumours. John Wiley \& Sons, Hoboken, NJ, USA, 2017.

22 Oya M, Takahashi S, Okuyama T, Yamaguchi M and Ueda Y: Synchronous colorectal carcinoma: Clinico-pathological features and prognosis. Jpn J Clin Oncol 33: 38-43, 2003. PMID: 12604723.

23 Harada Y, Kazama S, Morikawa T, Murono K, Yasuda K, Otani K, Nishikawa T, Tanaka T, Kiyomatsu T, Kawai K, Hata K, Nozawa $\mathrm{H}$, Yamaguchi H, Ishihara S and Watanabe T: Leucine-rich repeatcontaining G protein-coupled receptor 5 and CD133 expression is associated with tumor progression and resistance to preoperative chemoradiotherapy in low rectal cancer. Oncol Lett 14: 7791-7798, 2017. PMID: 29250176. DOI: 10.3892/ ol.2017.7207

24 Nakano K, Yamamoto H, Fujiwara M, Koga Y, Tsuruta S, Ihara E, Oki E, Nakamura M, Ogawa Y and Oda Y: Clinicopathologic and molecular characteristics of synchronous colorectal carcinoma with mismatch repair deficiency. Am J Surg Pathol 42: 172-182, 2018. PMID: 28877066. DOI: 10.1097/ PAS.0000 000000000947

25 Reles A, Schmider A, Press MF, Schönborn I, Friedmann W, Huber-Schumacher S, Strohmeyer $\mathrm{T}$ and Lichtenegger W: Immunostaining of $\mathrm{p} 53$ protein in ovarian carcinoma: correlation with histopathological data and clinical outcome. J Cancer Res Clin Oncol 122: 489-494, 1996. PMID: 8698749.

26 Kawasaki T, Nosho K, Ohnishi M, Suemoto Y, Kirkner GJ, Dehari R, Meyerhardt JA, Fuchs CS and Ogino S: Correlation of beta-catenin localization with cyclooxygenase-2 expression and $\mathrm{CpG}$ island methylator phenotype (CIMP) in colorectal cancer. Neoplasia 9: 569-577, 2007. PMID: 17710160. DOI: 10.1593/neo.07334

27 Jass JR, Biden KG, Cummings MC, Simms LA, Walsh M, Schoch E, Meltzer SJ, Wright C, Searle J, Young J and Leggett BA: Characterisation of a subtype of colorectal cancer combining features of the suppressor and mild mutator pathways. J Clin Pathol 52: 455-460, 1999. PMID: 10562815.

28 Arakawa K, Hata K, Yamamoto Y, Nishikawa T, Tanaka T, Kiyomatsu T, Kawai K, Nozawa H, Yoshida M, Fukuhara H, Fujishiro M, Morikawa T, Yamasoba T, Koike K, Fukayama M and Watanabe T: Nine primary malignant neoplasms-involving the esophagus, stomach, colon, rectum, prostate, and external ear canalwithout microsatellite instability: A case report. BMC Cancer 18: 24, 2018. PMID: 29301504. DOI: 10.1186/s12885-017-3973-2

29 Tanaka J, Watanabe T, Kanazawa T, Tada T, Kazama Y, Tanaka $\mathrm{T}$ and Nagawa H: Left-Sided microsatellite unstable colorectal cancers show less frequent methylation of $h M L H 1$ and $\mathrm{CpG}$ island methylator phenotype than right-sided ones. J Surg Oncol 96: 611-618, 2007. PMID: 17786961. DOI: 10.1002/jso.20877

30 Tada T, Watanabe T, Kanazawa T, Kazama S, Koketsu S and Nagawa $H$ : Genetic characterization of colorectal cancers in young patients based on chromosomal loss and microsatellite instability. Scand J Gastroenterol 39: 1134-1140, 2004. PMID: 15545173. DOI: $10.1080 / 00365520410007881$

31 Herman JG, Graff JR, Myohanen S, Nelkin BD and Baylin SB: Methylation-specific PCR: A novel PCR assay for methylation status of CpG islands. Proc Natl Acad Sci USA 93: 9821-9826, 1996. PMID: 8790415.

32 Herman JG, Umar A, Polyak K, Graff JR, Ahuja N, Issa JP, Markowitz S, Willson JK, Hamilton SR, Kinzler KW, Kane MF, Kolodner RD, Vogelstein B, Kunkel TA and Baylin SB: Incidence and functional consequences of hMLH1 promoter hypermethylation in colorectal carcinoma. Proc Natl Acad Sci USA 95: 6870-6875, 1998. PMID: 9618505.

33 Arnold CN, Goel A, Compton C, Marcus V, Niedzwiecki D, Dowell JM, Wasserman L, Inoue T, Mayer RJ, Bertagnolli MM and Boland CR: Evaluation of microsatellite instability, $h M L H 1$ expression and $h M L H 1$ promoter hypermethylation in defining the MSI phenotype of colorectal cancer. Cancer Bio Ther 3: 7378, 2004. PMID: 14726676

34 Lynch HT, Lynch PM, Lanspa SJ, Snyder CL, Lynch JF and Boland CR: Review of the Lynch syndrome: History, molecular genetics, screening, differential diagnosis, and medicolegal ramifications. Clin Genet 76: 1-18, 2009. PMID: 19659756. DOI: $10.1111 /$ j.1399-0004.2009.01230.x

35 Mas-Moya J, Dudley B, Brand RE, Thull D, Bahary N, Nikiforova $\mathrm{MN}$ and Pai RK: Clinicopathological comparison of colorectal and endometrial carcinomas in patients with Lynch-like syndrome versus patients with Lynch syndrome. Hum Pathol 46: 1616-1625, 2015. PMID: 26319271. DOI: 10.1016/ j.humpath.2015.06.022

36 Chika N, Eguchi H, Kumamoto K, Suzuki O, Ishibashi K, Tachikawa T, Akagi K, Tamaru JI, Okazaki Y and Ishida H: Prevalence of Lynch syndrome and Lynch-like syndrome among patients with colorectal cancer in a Japanese hospital-based population. Jpn J Clin Oncol 47: 191, 2017. PMID: 28031357. DOI: $10.1093 /$ jjco/hyw200

37 Koyanagi K, Bilchik AJ, Saha S, Turner RR, Wiese D, McCarter M, Shen P, Deacon L, Elashoff D and Hoon DS: Prognostic relevance of occult nodal micrometastases and circulating tumor cells in colorectal cancer in a prospective multicenter trial. Clin Cancer Res 14: 7391-7396, 2008. PMID: 19010855. DOI: 10.1158/1078-0432.CCR-08-0290

38 Balschun K, Haag J, Wenke AK, von Schonfels W, Schwarz NT and Rocken C: KRAS, NRAS, PIK3CA exon 20, and BRAF genotypes in synchronous and metachronous primary colorectal cancers diagnostic and therapeutic implications. J Mol Diagn 13: 436-445, 2011. PMID: 21704278. DOI: 10.1016/j.jmoldx.2011. 03.002

39 Douillard JY, Oliner KS, Siena S, Tabernero J, Burkes R, Barugel M, Humblet Y, Bodoky G, Cunningham D, Jassem J, Rivera F, Kocakova I, Ruff P, Blasinska-Morawiec M, Smakal M, Canon JL, Rother M, Williams R, Rong A, Wiezorek J, Sidhu $\mathrm{R}$ and Patterson SD: Panitumumab-FOLFOX4 treatment and RAS mutations in colorectal cancer. N Eng J Med 369: 10231034, 2013. PMID: 24024839. DOI: 10.1056/NEJMoa1305275

\footnotetext{
Received January 22, 2019

Revised February 18, 2019

Accepted February 21, 2019
} 